\title{
Maja Rijavec HOW TO OUTDO THE TEXTBOOK
}

E FL teachers often complain about limitations their compulsory course books and textbooks place on their work, imposing a style of teaching which makes the process tiresome and unrewarding.

This chapter is addressed to those unlucky teachers of English who, apart from all the difficulties connected with teaching, have to cope with the textbook itself, often inadequate in many respects.

The most widespread deficiency of textbooks for children is the inadequate content of the texts. Conceptually poor or empty subject matter that cannot appeal to the young learners is usually accompanied by a dull and totally commonplace atmosphere, and totally unsuitable to arouse pupils' interests. I still remember one of my first lessons in German. The text, meant for 11-years-olds was entitled Die Bauerngenossenschaft (The Peasant Co-operative Society). No wonder I gave up learning the language altogether! The artificially constructed texts not only disregard learners' interests, but also underestimate their intellectual capacities and their knowledge of the world. They present a simplified version of what adults consider a child's world should be like. It is an ideal world of flat characters: loving parents, honest old men, hard-working peasants, impeccable teachers and sometimes naughty, but always happy children, uttering correct sentences about insignificant topics. It is amazing how interesting and relevant topics can be turned into dull ones by the edifying, matter-of-fact style commonly used in textbooks. In addition, tasks for practice included in textbooks usually allow little room for creativity. They roughly fall into two categories: grammar gymnastics and data reproduction. In this way, apart from being off-putting, the textbooks encourage only formal knowledge and do not contribute to general education as much as they could.

There is no such thing as an ideal textbook, yet we can imagine one. In theory, it would be a textbook designed for one specific teacher and learner pair, preferably by the teacher himself/herself. It would have to take into account the specific demands of the learner (his or her interests and abilities) as well as the teacher's. However, in practice we have to do with what we have and make the most of it.

In this chapter I would like to describe ways of handling elementary level texts, no matter how inadequate or poor they are, in order to make them more acceptable and more interesting.

First of all, we should free ourselves from the tyranny of the course book by changing our general attitude towards it. We should stop treating it as the Bible and feeling guilty in case we do not fulfil its purposes completely. A course book should be treated 
as a tool for achieving the ends of teaching, one that can be used as freely and creatively as the teacher finds it necessary. The improvements can cover several aspects: context, attitude towards the subject matter, characters, style, and form.

\section{How to improve the context}

Almost any context can be made more interesting by slight modifications achieved by introductory remarks or those made during or after the presentation of the text. Let's examine the unavoidable and the inevitable topics, such as sightseeing. A sightseeing tour itself can be very exciting, but an objective account of it leaves the average learner feeling quite indifferent. Picture postcards and slides do not help. A useful thing to do can be to mix a few personal or witty remarks into the presentation describing how the tourists experienced a particular sight or how they felt while visiting it. Another possibility is to add a final sentence that changes the whole context by an unexpected turn, even a shock. An element of surprise always makes the context more appealing. For example, we could tell the pupils that all they have heard is just what a tourist told his wife while, in fact, he spent the whole afternoon in the pub. We can then expand upon the new situation introducing fun and imagination. We can discuss why the person went to the pub, what he did there, whom he met, etc. From the language point of view such a conversation could be more useful than learning data about the sights of a city most of the pupils will never visit. The context can be changed in still another way: by presenting the given text as part of a larger whole. Following this principle we can turn a sightseeing tour into a detective story. Pupils can be asked to help with the case by giving detailed description of the places where they saw the suspect. We can also create an attractive context for the sightseeing vocabulary if the pupils pretend to be taking ET round and telling him about the sights. Elements of mystery and suspense introduced in this way have proved to be highly motivating. Still another way of changing the context is to replace a sentence or two so that the title is no longer appropriate and ask the pupils to find a more suitable one. We can also ask them to divide the text into several parts and change the story by changing their order. Furthermore, almost any text can be presented as a series of predictions. In a step by step presentation the children are involved in creating the story and may offer several versions of the text, which can be written down, compared, and discussed. The original textbook version can be used just for comparison or to consolidate language items. The teacher can also rewrite the text changing or omitting details and then provide the revised version as handouts for pupils to correct by comparing it with the original version. Of course, with young children the most rewarding method is to turn every subject-matter into a story or a game. 


\section{How to change the attitude}

When we examine a given text from a different perspective we are set free to play with it. With older pupils we can arouse their interest by allowing them to criticize the text. They can discuss whether they like it or not and why, whether it is convincing or silly, which part of the text is the best, etc. Then they can select good points and correct poor ones. With younger children the best change is to introduce humour. Everything can be analysed from a humorous point of view. We can make fun of the text itself, of the characters and their relationships. Information presented in the text can be rearranged in a funny way. Sentences can be combined in an unusual order and we can turn the text upside down and still preserve its purpose of teaching language. Here is an illustration of this technique. The original text reads as fallows:

"We can tell the time by means of watches and clocks. A watch is carried in a waistcoat pocket or is worn on the wrist with a strap or ribbon. A clock is too big for a pocket and is placed on the mantelpiece or is hung on the wall. The big clocks that stand on the floor are called grandfather clocks."

This is the humorous variation:

"Grandfather clocks stand on the floor in their waistcoats. We can tell the time if our pocket is hung on the wall or if we place our wrist on the mantelpiece. If a watch is too big to be worn on a ribbon it is called a clock."

Besides having fun the pupils will unperceptably learn the words and the structures in order to be able to produce such a piece of writing.

\section{How to overcome the typical textbook style}

A dull, matter-of-fact style is not easy to utilize advantageously. It certainly discourages the young readers but an improvement would require adding a pinch of artistic flavour which only rare persons are able to do. What every teacher can do is to insert a sentence or two to stir emotions and shift the whole thing to another register. For example:

Many duties are carried out at the Post Office. Letters are delivered, telephone and bank services are provided, postal orders are sold, and wires are sent.

Addition: Clearly that's why the postman didn't have time to deliver Michael's letter! I've been waiting for a month.

\section{How to improve characters}

This is the easiest part of the problem. Textbook characters usually have no character traits. Thus, we are free to decide what kind of persons they might be, describe them 
and modify their utterances according to their assumed personality. Children love attributing qualities, describing looks and clothes as well as feelings and problems of the characters they meet. They can also introduce new characters to enrich the story.

\section{How to improve form}

A text, in terms of form can be too difficult, too easy, or the order of presentation can be wrong. In the first case we can simplify it to the point that suits our pupils' level of knowledge, photocopy the simplified version and work on it in class until pupils are prepared to acquire the original one. I would not recommend to cut the text into shorter parts because it would add to the previously mentioned conceptual emptiness and put further stress on mastering linguistic form outside a meaningful context.

On the other hand, if the text is too simple, we can enrich it by loading it with appropriate vocabulary or structure items in every imaginable way. Some of the ways have been suggested above.

A textbook is usually not designed as an open material, but we can cut it open and use its contents in whatever way we like. We should bear in mind that our job is to teach English, not the textbook lessons.

Still, I must admit there are examples beyond revision. The Bauerngenossenschaft example definitely needs to be excluded. 